\title{
Internet-Based Supportive Education Intervention to Physical Activity of Cancer Survivors: A Scoping Review
}

\author{
Jajang Ganjar Waluya ${ }^{1}$, Laili Rahayuwati² and Mamat Lukman² \\ 1Puskesmas Cipanas Lebak; jajangganjarwaluya@gmail.com \\ 2 Faculty of Nursing, Universitas Padjadjaran; lailira2002@yahoo.com \\ 2 Faculty of Nursing, Universitas Padjadjaran; mamat_lukman@yahoo.com \\ *Corresponding author: jajangganjarwaluya@gmail.com ; Tel.: 085780834408 \\ Type of the Paper ( Review)
}

Received: May 30, 2019; Accepted: July 30, 2019; Published: August 12, 2019

https://doi.org/10.29253/achnr.2019.1717

\begin{abstract}
Cancer survivors are at risk of decreasing health and psychosocial problems. Physical activity can reduce the risk of recurrence, death, and negative effects of cancer treatment. Several studies have investigated how the use of internet technology can increase the physical activity of survivors of cancer. The purpose of this review is to explore and identify the types of internet-based supportive education interventions to increase the physical activity of cancer survivors. We followed the methodology for scoping studies which consists of identifying the research question, locating relevant studies, selecting studies, charting the data, and collating, summarizing, and reporting the results. The search method used several electronic databases namely Google Scholar, Proquest, PubMed, and Scopus. Articles obtained from keywords: internet-based; supportive education; physical activity; cancer survivors. The inclusion criteria are: peer reviewed articles, publication year from 2008 to 2018 and has a minimal research design quasi experiment. Out of 5375 original articles identified in the literature search, 15 articles were analysed. Online support groups are the most frequently studied method of educational intervention, followed by interactive messages and web forums. Most studies showed improved results on intensity of physical activity. Online groups can improve the wellbeing of survivors of cancer by providing opportunities to engage in social networking, connect with others with similar cancer experiences, and obtain cancer related information. Based on the findings of this review. Supportive education through internet technology approaches can encourage increased physical activity and changes in health behavior of survivors of cancer. Future research should consider the potential role of social media in addressing the unmet needs of survivors of cancer and in particular the implications for clinical and public health practice.
\end{abstract}

Keywords: internet-based; supportive education; physical activity; cancer survivors

\section{Introduction}

Cancer is the second leading cause of death in the world, and it's responsible for 8.8 million deaths by 2015. Globally, nearly 1 in 6 deaths are caused by cancer. It's indicates that cancer is one of the six most deadly diseases that affect the mortality rate of the world. The most common cause of death from cancer is lung cancer that is 1.69 million deaths (Stewart \& Wild, 2014). 
Advances in early diagnosis and treatment of cancer have an impact on increasing survival of cancer survivors. While survivors of cancer who have successfully completed their primary treatment hope to be able to return to work or back to life before being diagnosed with cancer.

Cancer survivors are at risk of decreased health and psychosocial problems. Cancer treatment can lead to increased fatigue, decreased physical activity, and decreased quality of life (Fong et al., 2012). Long term negative consequences of cancer and treatment related side-effects are common and often debilitating. Pain problem, sleep problems, physical side effects (e.g. lymphoedema), weight gain, anxiety and depression, fear of cancer recurrence and impaired quality of life (QoL) are all commonly reported (Roberts et al., 2017).

Physical activity is an intervention that potentially relieves cancer-related residual symptoms and helps patients return to the health status before treatment. Physical activity participation has been associated with reduced cancer-specific and all-cause mortality in breast and colorectal cancer survivors. Furthermore, PA participation is associated with better quality of life and psychological health of cancer survivors (Park et al., 2016).

Several training programs have been developed and tested to encourage cancer survivors to participate in physical activity including education and counseling. Several studies have shown that recommendations from oncologists, exercise suggestions, and sports education have managed to motivate patients to increase the amount of their physical activity especially when combined with telephone or community support (Patrick, Pratt, \& Sallis, 2009). Furthermore, Vallance et al. also reported that giving physical print media and pedometer is an effective tool to increase the level of physical activity among survivors of breast cancer (Vallance J K, et al, 2007).

The development and widespread use of internet technology, smartphones and mobile technology has driven the intervention of changes in digital health behavior. Ofcom Communications Market report for the UK has shown that the proportion of adults going online using a mobile phone has risen from $20 \%$ in 2009 to $66 \%$ in 2016 and $71 \%$ of adults own a smartphone (Ofcom, 2017). Use of internet technology such as email, mobile apps, video conferences (e.g. Skype), social media, websites and online patient portals that improve access to information, connecting patients with health care and as approach to remote behavior change interventions (Roberts et al., 2017).

Among internet applications is an effort to promote the participation of physical activity and dietary behavior such as research by Mateo et al in 2015. The results show that cell phone-based interventions are associated with weight loss and improvement physical activity showed significant improvement. Mobile-based application interventions can be a useful tool for improving physical activity and dietary interventions (Mateo et al., 2015). The aim of this review is to explore and identify the types of internetbased supportive education interventions to increase the physical activity of cancer survivors.

\section{Methods}

We followed the methodology for scoping studies which consists of identifying the research question, locating relevant studies, selecting studies, charting the data, and collating, summarizing, and reporting the results.

\subsection{Identifying the research question}

We sought to answer related research questions: What are the educational interventions based on the internet to increase the physical activity of cancer survivors?

\subsection{Identifying relevant studies}

The literature study was done by publishing a published (resume) of research articles related to the research question. The search method used several electronic databases namely Google Scholar, Proquest, PubMed, and Scopus. Articles obtained from keywords: internet-based; supportive education; physical activity; cancer survivors Literature searches were completed on March 2, 2018. Relevant articles retrieved from the reference lists of relevant and selected articles were also included for screening.

\subsection{Study selection}


The inclusion criteria in this literature study were (1) study participants were individuals with a history of cancer who had completed active treatment (2) research article has peer review, full text and English language, (3) title and content relevant to research questions, (4) publication year from 2008 to 2018 and has a minimal research design quasi experiment. Exclusion criteria included articles that do not have the structure of a good article (consisting of abstract, introduction, methods, results, discussions, implications, and references), review articles and article content cannot answer research questions.

\subsection{Charting the data and quality assessment}

We performed the data extraction containing categorical domains, which could provide a clear and systematic description of the chosen articles. Microsoft Excel was used to summarize the relevant data. During data extraction, we analyzed the full texts of all 15 primary papers. Then we read the assigned articles and extracted the required data from the articles in order to answer the research questions. We collected three kinds of information from each paper. In the first step, standard information was gathered, like title of the article, place of research, sample size and research design.

The second and third steps included information directly related to answering the previously defined research questions. In the second step, the goal was to identify for type of cancer, physical activity measures and physical activity outcomes. The final step included gathering information about Interventions type, study duration and outcomes for included studies and the evaluation of the intervention.

\section{Results (or Results and Discussion)}

\subsection{Study selection}

We found 5375 studies through database searches. See figure 1 for the diagram of the study selection process. The search strategy initially identified 5375 records. Of these, 2112 articles were removed because duplicates, 2714 were excluded because of irrelevance to the topic. Strict inclusion criteria, as outlined above were applied to the full text of 93 articles. Of these, 15 were included in the final review. The majority of studies were published between 2012 and 2018, with one study published in 2011 and four in 2014. Sample sizes ranged between 10 and 352. All 15 studies assessed the impact of the internet base supportive education intervention on cancer survivor.

See table 1 for distribution of research sites and table 2 for research design. The majority of studies were located in USA and only one study took place in Asia. Fourteen studies were RCTs, and the remaining one was pre-post comparison studies.

Table 1. Distribution of research places.

\begin{tabular}{lc}
\hline Place of research & Number of articles \\
\hline United States & 8 \\
South Korea & 1 \\
Canada & 1 \\
UK & 2 \\
Netherlands & 1 \\
Australia & 2 \\
Total & 15 \\
\hline
\end{tabular}


Table 2. Research design

\begin{tabular}{lcl}
\hline Design & $\begin{array}{l}\text { Number } \\
\text { of } \\
\text { Articles }\end{array}$ & \multicolumn{1}{c}{ Method } \\
\hline Kuantitatif & 11 & $\begin{array}{l}\text { Randomized Control } \\
\text { Trial (RCT) } \\
\text { Pretest-Posttest } \\
\text { design } \\
\text { RCT dan Kualitatif }\end{array}$ \\
\hline
\end{tabular}

\subsection{Type of cancer}

The majority of studies were breast cancer survivor that is 8 studies. Others are all types of cancers that have completed primary treatment, colorectal cancer and gynecological cancer.

We structured the results into three categories based on type of intervention, description of intervention, and outcomes. By organizing the paper in this way, we were able to systematically evaluate the evidence pertaining to each group, see how they interrelated, and were also able to evaluate for gaps in the literature. The outcomes that we focused on in this paper included various aspects of internetbased intervention to increase physical activity of cancer survivors.

\subsection{Type of intervention}

Based on the results of the review, the types of internet-based supportive education interventions to increase physical activity of cancer survivors are mobile application, online support group, email, social media posts, online workshop, My Tools, and help center. In addition there are also websites, social networking intervention programs, videosharing, LIFE Community, and Facebook-based interventions. All interventions can increase physical activity in cancer survivors.

\subsection{Physical activity measures}

All 15 included studies measured the impact of internet-based education on phisycal activity. All used self-reported PA as outcomes. Majority physical activity was assessed using Godin Leisure Time Exercise Questionnaire (GLTEQ) (8 studies) and the others use IPAQ, Seven-day Physical Activity Recall (PAR), Patient-Centered Assessment and Counseling for Exercise questionnaire. Short et al., (2017) also reported a resistance training score. McCarroll et al.,(2015) reported number of minutes of phisycal activity completed and the number of calories expended as logged via the participant using the mobile app used for their intervention. Puszkiewicz et al., (2016) calculate a combined moderate-vigorous phisycal activity variable.

\subsection{Physical activity outcomes}

Most studies show improved results on intensity of physical activity. Participants in the internetbased intervention had significantly greater increases in minutes per week of vigorous exercise and stretching compared to controls (Bantum et al., 2014). Research by Pope, (2018) showed increases for average daily moderate to vigorous physical activity duration (2.6-min increase). In addition there was an increase in self-efficacy related to physical activity (3\%), There was a significant increase in moderatestrong aerobic activity observed in all study groups. The online module intervention provides preliminary evidence that web-based interventions can be used to increase physical activity among breast cancer survivors. (Short et al., 2017). Multi-intervention approaches have shown more positive results than single interventions. 


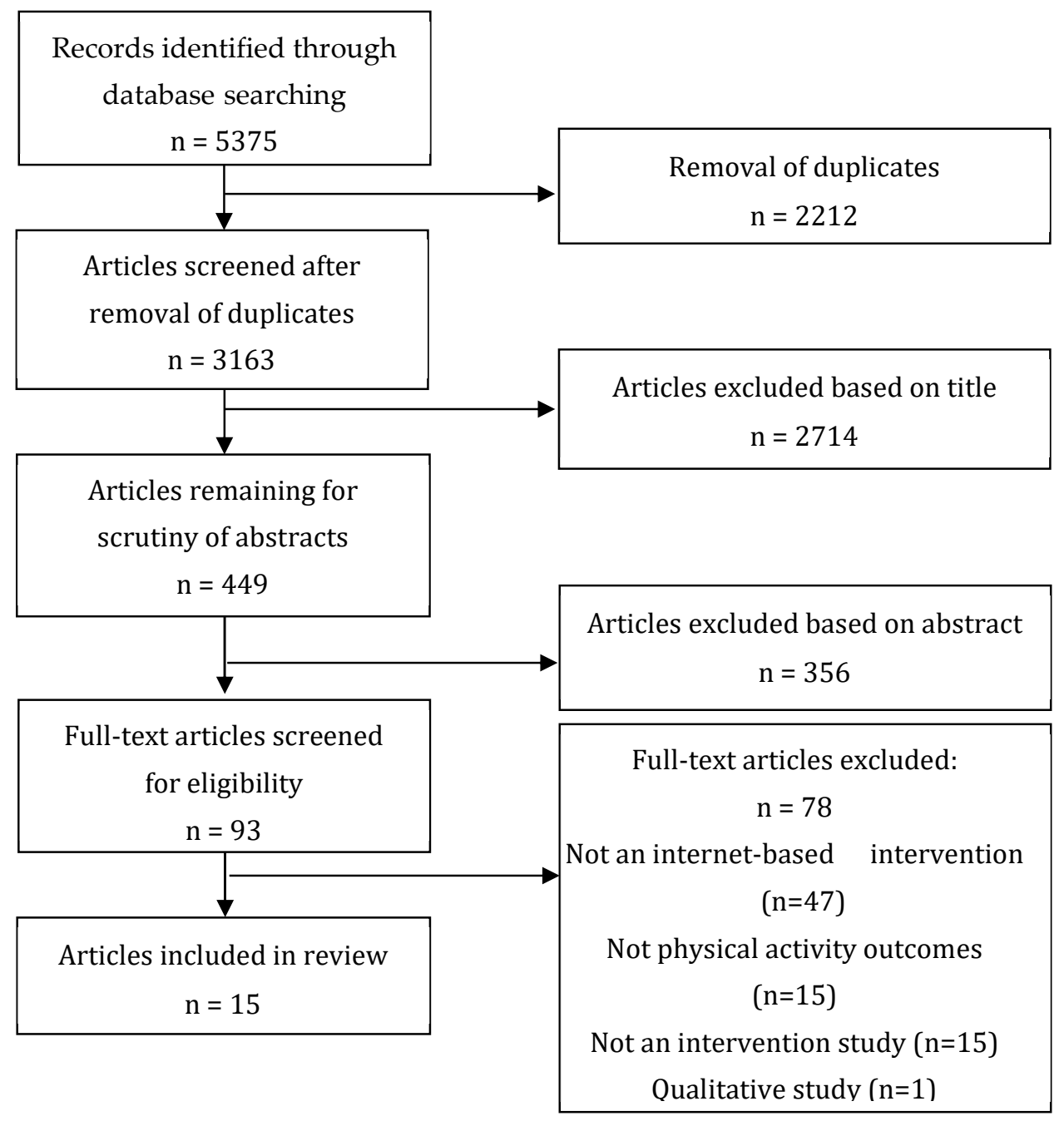

Figure 1. Diagram illustrating article selection strategy. 
Table 3. Characteristics of included studies.

\begin{tabular}{|c|c|c|c|c|c|c|}
\hline No & Author & Article title & Country & $\begin{array}{l}\text { Study } \\
\text { Design }\end{array}$ & $\begin{array}{l}\text { Sample } \\
\text { size }\end{array}$ & Cancer type(s) \\
\hline 1 & Pope et al., (2018) & $\begin{array}{l}\text { Feasibility of Smartphone Application and Social Media } \\
\text { Intervention on Breast Cancer Survivors' Health Outcomes }\end{array}$ & USA & RCT & 10 & Breast cancer survivors \\
\hline 2 & Forbes et al., (2015) & $\begin{array}{l}\text { Feasibility and Preliminary Efficacy of an Online } \\
\text { Intervention to Increase Physical Activity in Nova Scotian } \\
\text { Cancer Survivors: A Randomized Controlled Trial }\end{array}$ & Canada & RCT & 87 & $\begin{array}{l}\text { Breast, prostate and colorectal } \\
\text { cancer survivors. }\end{array}$ \\
\hline 3 & $\begin{array}{l}\text { Bantum et al., } \\
(2014)\end{array}$ & $\begin{array}{l}\text { Surviving and Thriving With Cancer Using a Web-Based } \\
\text { Health Behavior Change Intervention: Randomized } \\
\text { Controlled Trial }\end{array}$ & USA & RCT & 352 & Any type of cancer survivors. \\
\hline 4 & Rabin et al., (2011) & $\begin{array}{l}\text { Internet-based Physical Activity Intervention Targeting } \\
\text { Young Adult Cancer Survivors }\end{array}$ & USA & RCT & 18 & Any type of cancer survivors, \\
\hline 5 & Short et al., (2017) & $\begin{array}{l}\text { How do Different Delivery Schedules of Tailored web-based } \\
\text { Physical Activity Advice for Breast Cancer Survivors } \\
\text { influence Intervention Use and Efficacy? }\end{array}$ & Australia & RCT & 492 & Breast cancer survivors \\
\hline 6 & $\begin{array}{l}\text { Valle et al., } \\
(2014)\end{array}$ & $\begin{array}{l}\text { A Randomized Trial of A Facebook-Based Physical Activity } \\
\text { Intervention for Young Adult Cancer Survivors }\end{array}$ & USA & RCT & 86 & Any type of cancer survivors \\
\hline 7 & $\begin{array}{l}\text { Valle \& Tate, } \\
\text { (2017) }\end{array}$ & $\begin{array}{l}\text { Engagement of Young Adult Cancer Survivors Within A } \\
\text { Facebook-Based Physical Activity Intervention }\end{array}$ & USA & RCT & 86 & $\begin{array}{l}\text { Any type cancer (excluding non- } \\
\text { melanoma skin cancer) }\end{array}$ \\
\hline 8 & $\begin{array}{l}\text { Hawkes et al., } \\
(2012)\end{array}$ & $\begin{array}{l}\text { Canprevent: A Telephone-Delivered Intervention To Reduce } \\
\text { Multiple Behavioural Risk Factors for Colorectal Cancer }\end{array}$ & Australia & RCT & 22 & Colorectal cancer survivors \\
\hline 9 & $\begin{array}{l}\text { McCarroll et al., } \\
(2015)\end{array}$ & $\begin{array}{l}\text { Feasibility of a lifestyle intervention for overweight/ obese } \\
\text { endometrial and breast cancer survivors using an } \\
\text { interactive mobile application }\end{array}$ & USA & Pre-Post & 35 & $\begin{array}{l}\text { Breast and / or endometrial cancer } \\
\text { survivors }\end{array}$ \\
\hline 10 & Kuijpers et al., (2016) & $\begin{array}{l}\text { eHealth for Breast Cancer Survivors: Use, Feasibility and } \\
\text { Impact of an Interactive Portal }\end{array}$ & $\begin{array}{l}\text { Netherland } \\
\mathrm{s}\end{array}$ & Pre-Post & 73 & Breast cancer survivors, \\
\hline 11 & Valle et al., (2015) & $\begin{array}{l}\text { Exploring Mediators of Physical Activity in Young Adult } \\
\text { Cancer Survivors: Evidence from a Randomized Trial of a } \\
\text { Facebook-Based Physical Activity Intervention }\end{array}$ & USA & RCT & 86 & Young adult cancer survivors \\
\hline 12 & $\begin{array}{l}\text { Donnelly et al., } \\
(2013)\end{array}$ & $\begin{array}{l}\text { A focus group study exploring gynecological cancer } \\
\text { survivors' Experiences and perceptions of participating in a } \\
\text { rct testing The efficacy of a home-based physical activity } \\
\text { intervention }\end{array}$ & UK & $\begin{array}{l}\text { RCT, Mix } \\
\text { Method }\end{array}$ & 64 & Gynecological cancer survivors \\
\hline
\end{tabular}




\begin{tabular}{|c|c|c|c|c|c|c|}
\hline 13 & $\begin{array}{l}\text { Hatchett et al., } \\
\text { (2013) }\end{array}$ & $\begin{array}{l}\text { Evaluation Of A Social Cognitive Theory-Based Email } \\
\text { Intervention Designed To Influence The Physical Activity Of } \\
\text { Survivors Of Breast Cancer }\end{array}$ & USA & RCT & 74 & Breast cancer survivors \\
\hline 14 & Lee et al., (2014) & $\begin{array}{l}\text { A Web-Based Self-Management Exercise And Diet } \\
\text { Intervention For Breast Cancer Survivors: Pilot Randomized } \\
\text { Controlled Trial }\end{array}$ & $\begin{array}{l}\text { South } \\
\text { Korea }\end{array}$ & RCT & 57 & Breast cancer survivors \\
\hline 15 & $\begin{array}{l}\text { Puszkiewiczet al., } \\
(2016)\end{array}$ & $\begin{array}{l}\text { Assessment of Cancer Survivors' Experiences of Using a } \\
\text { Publicly Available Physical Activity Mobile Application }\end{array}$ & UK & Pre-Post & 11 & $\begin{array}{l}\text { Breast, prostate or } \begin{array}{r}\text { colorectal } \\
\text { cancer survivors, } \\
\text { treatment }\end{array} \\
\text { completed }\end{array}$ \\
\hline
\end{tabular}

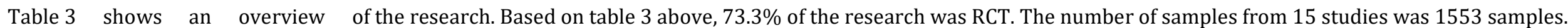
The majority $(53,3 \%)$ of studies were breast cancer survivors. The majority of studies were located in USA and only one study took place in Asia.

Table 4. Description of Intervention

\begin{tabular}{|c|c|c|c|}
\hline Author, Year & Intervention type & Study Duration & Description of Intervention \\
\hline $\begin{array}{l}\text { Pope et al, } \\
(2018)\end{array}$ & $\begin{array}{lr}\text { Mobile } & \text { Aplication, } \\
\text { facebook } & \text { support } \\
\text { group } & \end{array}$ & 10 weeks & $\begin{array}{l}\text { Participants download the MapMyFitness app, document all physical activity with MapMyFitness, and enroll } \\
\text { in educational health education interventions of Social Cognitive Theory. Physical activity, body weight or } \\
\text { body composition are objectively measured, cardiovascular fitness, psychosocial constructs, and quality of } \\
\text { life indices are measured at baseline and } 10 \text { weeks. Use and acceptance of interventions are evaluated } \\
\text { during and after intervention }\end{array}$ \\
\hline $\begin{array}{l}\text { Forbes et al., } \\
(2015)\end{array}$ & $\begin{array}{l}\text { Online workshop } \\
\text { (Website) }\end{array}$ & 10 weeks & $\begin{array}{l}9 \text { week workshop to deliver content (e.g. dispelling physical activity myths, exercising safely, } \\
\text { planning/making SMART goals). Website used to log/monitor physical activity and email feed back. }\end{array}$ \\
\hline $\begin{array}{l}\text { Bantum et al, } \\
\text { (2014) }\end{array}$ & $\begin{array}{l}\text { Discussion Center, } \\
\text { My Tools, } \\
\text { Help Center. }\end{array}$ & $\begin{array}{l}6 \text { weeks } \\
\text { programs }\end{array}$ & $\begin{array}{l}\text { The Surviving and Thriving with Cancer (STC) Intervention is a six-week online workshop adapted from } \\
\text { (CDSMP), a patient education course that adopts the basic principle that people with the same health } \\
\text { conditions can help each other improve their health behaviors. To create the STC program, the web-based } \\
\text { CDSMP version is adapted to make it more relevant for cancer patients. }\end{array}$ \\
\hline $\begin{array}{l}\text { Rabin et al, } \\
(2011)\end{array}$ & $\begin{array}{l}\text { Online forum } \\
\text { discussion, Weekly } \\
\text { email }\end{array}$ & 12 weeks & $\begin{array}{l}\text { Intervention: granted } 12 \text { week website access. The website intervention is based on the Step into Motion } \\
\text { (SIM) website developed by Dr. Bess Marcus et al. } 30 \text { The original SIM website, based on the } \\
\text { Transtheoretical model and the social cognitive theory, is designed to promote physical activity among adult } \\
\text { settlers in the general population. }\end{array}$ \\
\hline $\begin{array}{l}\text { Short et al., } \\
(2017)\end{array}$ & $\begin{array}{l}\text { Online workshop } \\
\text { (website) }\end{array}$ & 12 weeks & $\begin{array}{l}3 \text { online modules intervention delivered monthly, a three-module intervention delivered weekly or a single } \\
\text { module intervention. The modules shipped with a combination of unadjusted information (Physical activity } \\
\text { guidance, motivation and prevention relapse) and tailored to support (eg based on health status of social } \\
\text { support,) }\end{array}$ \\
\hline
\end{tabular}




\begin{tabular}{|c|c|c|c|}
\hline $\begin{array}{l}\text { Valle et al, } \\
(2014)\end{array}$ & $\begin{array}{l}\text { Facebook support } \\
\text { group + website }\end{array}$ & 12 weeks & $\begin{array}{l}\text { Weekly messages (sent via Facebook) and group administrators post discussions in groups across } \\
\text { interventions. Participants also have access to websites for regulatory purposes and diary of physical } \\
\text { activity and pedometers to measure steps. }\end{array}$ \\
\hline $\begin{array}{l}\text { Valle \& Tate, } \\
\text { (2017) }\end{array}$ & $\begin{array}{l}\text { Facebook support } \\
\text { group + website }\end{array}$ & 12 weeks & $\begin{array}{l}\text { FITNET Intervention (Pedometer,12 weekly Facebook messages, Links to publicly available } \\
\text { websites,Lessons with guidance on physical activity and behavior strategies, Facebook groups with } \\
\text { moderated discussion guide) }\end{array}$ \\
\hline $\begin{array}{l}\text { Hawkes et al., } \\
\text { (2012) }\end{array}$ & $\begin{array}{l}\text { Telephone } \\
\text { health coaching } \\
\text { sessions, } \\
\text { DigiWalker } \\
\text { Pedometer }\end{array}$ & 6 weeks & $\begin{array}{l}\text { The intervention included six evidence based telephone health coaching sessions delivered by study trained } \\
\text { health professionals (health coaches), and a participant handbook, worksheets and a Yamax SW700 } \\
\text { Multifunction Digi Walker pedometer. } \\
\text { The program focuses on supporting positive lifestyle changes (physical activity, diet, weight management, } \\
\text { alcohol and smoking) and for taking CRC screening is consistent with national guidelines. }\end{array}$ \\
\hline $\begin{array}{l}\text { (McCarroll et } \\
\text { al., 2015) }\end{array}$ & Mobile application & 4 weeks & $\begin{array}{l}\text { Participants log nutrition / physical activity through app which provided real time personalised feedback. } \\
\text { Limited carbohydrate intake to }<70 \mathrm{~g} / \text { day and increase fibre intake to } 30 \mathrm{gr} / \text { day. }\end{array}$ \\
\hline $\begin{array}{l}\text { (Kuijpers et } \\
\text { al., 2016) }\end{array}$ & $\begin{array}{l}\text { Website (Online } \\
\text { portal) }\end{array}$ & 4 months & $\begin{array}{l}\text { Offers personalised education materials, overview of appointments, access to electronic medical record } \\
\text { (EMR). Tailored physical activity support based on clinical characteristics, physical activity levels and } \\
\text { motivation. }\end{array}$ \\
\hline $\begin{array}{l}\text { (Valle et al., } \\
2015)\end{array}$ & $\begin{array}{l}\text { Facebook-based } \\
\text { intervention } \\
\text { (FITNET) }\end{array}$ & 12 weeks & $\begin{array}{l}\text { 12-week randomized trial compared with Facebook-based intervention (FITNET) aimed at increasing the } \\
\text { intensity of moderate to strong physical activity into a Facebook-based self-help comparison group. } \\
\text { Survivors of young adult cancer }(\mathrm{N}=86 \text {, age } 21-39 \text { years) were randomly assigned to one of two groups. } \\
\text { Measurements of self-reports of physical activity and psychosocial variables were collected at baseline and } \\
\text { after } 12 \text { weeks. }\end{array}$ \\
\hline $\begin{array}{l}\text { (Donnelly et } \\
\text { al., 2013) }\end{array}$ & $\begin{array}{l}\text { home-based } \\
\text { programme }\end{array}$ & 12 weeks & $\begin{array}{l}\text { Suggestions for improvement include: opportunities for social interaction with other gynecological cancer } \\
\text { survivors and better exercise options }\end{array}$ \\
\hline $\begin{array}{l}\text { (Hatchett et } \\
\text { al., 2013) }\end{array}$ & $\begin{array}{l}\text { Email + access to } \\
\text { e-counsellor }\end{array}$ & 12 weeks & $\begin{array}{l}\text { Emails designed to increase physical activity by affecting Social Cognitive Theory variables. } \\
\text { E-conselor offers tailored physical activity and encourages participant involvement } \\
\text { in intervention }\end{array}$ \\
\hline $\begin{array}{l}\text { (Lee et al., } \\
2014)\end{array}$ & $\begin{array}{l}\text { Website + text } \\
\text { Messaging }\end{array}$ & 12 weeks & $\begin{array}{l}\text { Websites used for assessment, education, information, provision and action planning (goal setting, } \\
\text { scheduling, monitoring and } \\
\text { automatic feedback). Automatic feedback is provided daily on the actual and recommended behavior. }\end{array}$ \\
\hline $\begin{array}{l}\text { (Puszkiewicz } \\
\text { et al., 2016) }\end{array}$ & $\begin{array}{l}\text { Mobile application } \\
\text { (GAINFitness) }\end{array}$ & 6 weeks & $\begin{array}{l}\text { Tailored physical activity programme using video demonstrations is recommended based on users } \\
\text { preferred physiscal activity goals, duration, type and difficulty. }\end{array}$ \\
\hline
\end{tabular}

Based on table 4 above, the shortest duration of intervention time is 4 weeks and the longest intervention is 4 months. The average intervention time was 9.5 weeks. Most interventions used a duration of 12 weeks (53.3\%). 
Table 5. Outcomes in Physical Activity

Author, Year Outcomes

$\begin{array}{ll}\text { Pope et al, (2018) } & \begin{array}{l}\text { In post intervention, increases were observed for average daily moderate to vigorous physical activity duration (2.6-min increase), with } \\ \text { decreased average daily light physical activity and sedentary behavior seen as well. Improved physical activity-related self-efficacy (3\% }\end{array}\end{array}$ decreased average daily light physical activity and sedentary behavior seen as well. Improved physical activity-related self-efficacy ( $3 \%$
increase), social support ( 0.56 point increase), and enjoyment (0.15-point increase) were observed.

Forbes et al., Results were more pronounced, though still non significant, among those not meeting guidelines at baseline where UCAN increased physical (2015) activity by 52 minutes compared to a decrease of 15 minutes in UC (adjusted between group difference=75, $95 \%$ CI -95 to $244 ; \mathrm{P}=.38$, $\mathrm{d}=0.27$ ). There was a trend toward increased activity especially among inactive cancer survivors, although no significant differences were found.

Bantum et al, Participants of Web-based interventions experienced significant insomnia reductions and greater increases in minutes per week of physical (2014) exercise and strong stretching compared with controls.

Rabin et al, (2011) The findings revealed that 86\% of the participants in the group's website would recommend intervention to others and most (71\%) were satisfied or very satisfied with it. Furthermore, $100 \%$ votes go to the website as very easy and $86 \%$ of the site's information is rated as very easy to understand. The logging feature, followed by feature goal setting, is most commonly accessed by participants. Participants also rated graphs and stage-matched useful manual features. The approximate effect size for differences between groups at 12 weeks was moderate for the results of physical activity and great for psychosocial outcomes. Interventions of internet based physical activity in young adult cancer survivors are feasible and acceptable and can be profitable

Short et al., (2017) This study provides preliminary evidence that interventions tailored to web-based computers can be used to increase physical activity among survivors of breast cancer. There was a significant increase in moderate-vigorous aerobic activity observed across all study groups. However, there were no significant effects of group observed on moderate-vigorous aerobic activity in either analysis (all ps $<0.05$ ).

Valle et al, (2014) Over 12 weeks, both groups increased self-reported weekly minutes of moderate to vigorous physical activity (FITNET: 67 minutes/week, $\mathrm{p}=0.009$ vs. SC: 46 minutes/ week, p=0.045), with no significant difference between groups. Increases in light PA were 135 minutes/ week greater in the FITNET group relative to the SC group ( $\mathrm{p}=0.032)$, and the FITNET group reported significant weight loss over time $(-2.1 \mathrm{~kg}$ $\mathrm{p}=0.004 ; \mathrm{p}=0.083$ between groups).

The Facebook based intervention approach shows the potential for increased physical activity in young adult cancer survivors. Social networking sites may be a viable way for young adult cancer survivors to receive health information and support to promote physical activity and healthy behaviors.

Valle \& Tate, (2017) Participants agreed that group discussion caused them to become physically active ( $\mathrm{p}=0.040)$ and support group members ( $\mathrm{p}=0.028$ ). The post initiated by the participants gets more comments and likes significantly than moderator initiated posts.

Response posts on Facebook significantly predicted light physical activity at 12 weeks, such that every increase of one response post in Facebook was associated with an increase of approximately $12 \mathrm{~min} /$ week in light-intensity PA $(\beta=11.77, \mathrm{t}(85)=1.996, \mathrm{p}=0.049)$

Hawkes et al., From baseline to six weeks, improvements were observed for minutes moderate to vigorous physical activity (150.7 minutes).

(2012) The research is acceptable and they will recommend it to others at risk of colorectal cancer. The positive behavioral changes achieved through this intervention approach have the potential to impact on the development of colorectal cancer and other cancers or chronic diseases. 


\begin{tabular}{|c|c|}
\hline $\begin{array}{l}\text { (McCarroll et al., } \\
\text { 2015) }\end{array}$ & $\begin{array}{l}\text { A significant improvement in pre- and post-intervention total WEL score was noted (99.38 } \pm 41.8 \text { versus } 120.19 \pm 47.1, p=0.043) \text {. No significant } \\
\text { differences were noted in FACT-G, macronutrient consumption, and physical activity patterns. }\end{array}$ \\
\hline $\begin{array}{l}\text { (Kuijpers et al., } \\
\text { 2016) }\end{array}$ & $\begin{array}{l}\text { Median vigorous physical activity increased significantly from } 0.0 \text { to } 360.0 \text { MET minutes per week for the total group (P=.017), although this } \\
\text { effect was not apparent in the subgroup analyses. }\end{array}$ \\
\hline (Valle et al., 2015) & $\begin{array}{l}\text { In both groups, social support from friends and self monitoring is positively associated with changes in the intensity of physical activity from } \\
\text { moderate to strong. The FITNET group reported lower self efficacy for sticking to exercise (mean change=-0.38;95\% CI:-0.62 to- } \\
0.12 ; \mathrm{p}=0.025 \text { ) and social support from friends on social networking websites (mean change }=-0.47 ; 95 \% \mathrm{CI}:-1.45 \text { to } 0.65 ; \mathrm{p}=0.039 \text { ) relative } \\
\text { to the self help comparison group over time. Changes in social support from friends on social networking websites partially mediated the } \\
\text { intervention effects on moderate to vigorous physical activity (mean indirect effect }=-22.4 ; 95 \% \text { CI:-62.0 to-2.8) in the unexpected direction. }\end{array}$ \\
\hline $\begin{array}{l}\text { (Donnelly et al., } \\
\text { 2013) }\end{array}$ & $\begin{array}{l}\text { The findings suggest that women survivors of gynecological cancer feel participation in physical activity is important and provides benefits } \\
\text { in terms of psychological well-being and improved physical function. Supports continuation of home-based program features. }\end{array}$ \\
\hline $\begin{array}{l}\text { (Hatchett et al., } \\
\text { 2013) }\end{array}$ & $\begin{array}{l}\text { Email based interventions based on Social Cognitive Theory can significantly affect the level of physical activity of breast cancer survivors. } \\
\text { The analysis reveals a significant difference at } 6 \text { weeks }(p=0.002) \text { between the groups. At } 12 \text { weeks for total days of exercise, a significant } \\
\text { differencewas found }(p<0.001) \text {. }\end{array}$ \\
\hline (Lee et al., 2014) & $\begin{array}{l}\text { Web-based programs that target changes in exercise and dietary behavior may be effective for breast cancer patients if the theory of the } \\
\text { Trans Theoretical Model has been used to inform program strategy. Moderate intensity aerobic exercise for at least } 150 \text { min per week ( }<< \\
0.0001) \text { and eating five servings of } F \& V \text { per day }(p=0.001) \text { significantly increased in the intervention group compared to controls. }\end{array}$ \\
\hline $\begin{array}{l}\text { (Puszkiewicz et al., } \\
\text { 2016) }\end{array}$ & $\begin{array}{l}\text { Pre post comparison showed significant increases in strenuous physical activity, improvements in sleep quality, and reductions in mild } \\
\text { physical activity. There were no significant changes in moderate physical activity or other psychosocial outcomes. }\end{array}$ \\
\hline
\end{tabular}




\section{Discussion}

The previous research among cancer survivors (Lee et al., 2014) and the meta-analysis by Davies et al (2012) found that computer-tailored physical activity programs had positive effects on physical activity. Previous reviews also indicate that Internet-delivered interventions have positive effects on physical activity levels (Lustria, Cortese, Noar, \& Glueckauf, 2009). Internet-based education interventions can be given to cancer patients who are either undergoing treatment or who have finished treatment

The majority of the studies used an online portal or website to deliver the intervention and only three studies used mobile applications. This study reported a significant effect of internet based supportive education to increase physical activity cancer survivors. Schmid et al. also reported that breast or colorectal cancer survivors who increased their physical activity by any amount between pre and post diagnosis showed a decreased total mortality risk $(\mathrm{RR}=0.61,95 \% \mathrm{CI} 0.46-0.80)$ compared to cancer survivors who did not change their physical activity level or who were insufficiently active pre diagnosis (Schmid \& Leitzmann, 2014). Different results are shown by McCarroll et al., (2015) where the increase in physical activity through mobile application intervention is not significant. Therefore, even small increases in moderate-vigorous physical activity post diagnosis are likely to be beneficial for cancer survivors.

The study showed that some cancer survivors are interested and willing to receive physical activity information through the internet; however, modifications to the website are necessary to optimize the effectiveness (Forbes et al., 2015)

Research by Puszkiewicz et al., (2016) using mobile application (GAINFitness) showed a significant increase in participants' strenuous physical activity between T0 (median=40, IQR=105) and T1 (median=120, IQR=150), ( $\mathrm{z}=-2.80, \mathrm{P}=.002)$. Research by Pope, Lee, \& Lee, (2018) using mobile app MapMyFitness and Facebook showed increases for average daily moderate to vigorous physical activity duration (2.6-min increase), with decreased average daily light physical activity and sedentary behavior seen as well [10]. Given the multitude of commercially available mobile device health applications and the large number of individuals who currently use mobile device health application and social mediabased health education intervention may show promise in promoting cancer survivors' physical activity.

As Increased physical activity has been shown to reduce the symptoms of post-cancer treatment (eg, fatigue) and improve quality of life, innovative and practical interventions are needed to help survivors of cancer in regulating physical activity behaviors. Given the large number of commercially available mobile device health applications and the large number of individuals currently using mobile devices, combined mobile healthcare apps and social media-based health education interventions can be developed in promoting the physical activity of cancer survivors.

It's possible that the intervention using a mobile app may be more effective than other types of Internet-based interventions due to widespread use and constant access to smartphones and the Internet. The latest Report Ofcom Communications Market conducted in the UK reported that $71 \%$ of adults in the UK have smartphones and 66\% use their smartphones to access the Internet most often. Therefore, it would be interesting for future studies to use mobile apps as a way of delivering interventions and comparing the effectiveness of mobile app interventions as compared to other Internet-based interventions because it can encourage higher levels of engagement.

The review has shown that there is a positive relationship between participants' compliance / involvement with interventions and positive physical health outcomes in various populations and behaviors, suggesting that efforts to increase effective engagement with internet-based education can improve the outcome of behavior change (Roberts et al., 2017).

Using an online portal or website to deliver interventions requires support of telecommunication infrastructure. The majority of studies take place in developed countries where their telecommunication infrastructure is advanced. While in developing countries where telecommunication infrastructure support is not enough to implement internet-based interventions will encounter many difficulties. As in Indonesia where there are still many areas that have no internet network. Including characteristics of cancer survivors' rates are mostly in the middle and lower socioeconomic population and based on village / city area of cancer cases more in rural than in urban areas. Implementing internet-based interventions will encounter many difficulties.

\section{Conclusions}

The purpose of this scoping review was to identify internet-based supportive educational interventions to increase physical activity of cancer survivors. When we used these guidelines to investigate type of intervention and outcomes, we find that education through internet technology approaches can increase physical activity and health behaviors of cancer survivors. Suggested physical 
activity is based on The American College of Sports Medicine that cancer survivors must follow physical activity guidelines for at least 150 minutes with moderate intensity physical activity per week (Schmid \& Leitzmann, 2014).

The findings of this scoping review showed that internet-based education can have a significant influence on changes in the increase in cancer survivors' physical activity. In addition, it is possible that interventions using cellular applications are more effective than other types of use and constant access to smartphones and the internet. Therefore, this is a challenge for future applications to use cellular applications compared to other applications to increase cancer survivors' physical activity.

All participants recommend interventions for future use. Physical activity interventions that combine commercially available mobile health applications and health interventions delivered on social media can promote specific physiological, psychosocial, and quality of life out comes among cancer survivors.

Future research should consider the potential role of social media in addressing the unmet needs of survivors of cancer and in particular the implications for clinical and public health practice.

Funding: This research received no external funding.

Conflicts of Interest: The authors declare no conflict of interest.

\section{References}

Bantum E O C, Albright C L, White K K, Berenberg J L, Layi G, Ritter P L and Lorig K 2014 Surviving and thriving with cancer using a web-based health behavior change intervention: Randomized controlled trial Journal of Medical Internet Research 16(2) e54

Donnelly C M, Lowe-Strong A, Rankin J P, Campbell A, Blaney J M, and Gracey J H 2013 A focus group study exploring gynecological cancer survivors' experiences and perceptions of participating in a RCT testing the efficacy of a home-based physical activity intervention Supportive Care in Cancer 21(6) 1697-708

Davies C, Spence J, Vandelanotte C, Caperchione C and Mummery W K 2012 Meta-analysis of internet-delivered interventions to increase physical activity levels International Journal of Behavioral Nutrition and Physical Activity 9(1) 52

Forbes C C, Blanchard C M, Mummery W K and Courneya K S 2015 Feasibility and Preliminary Efficacy of an Online Intervention to Increase Physical Activity in Nova Scotian Cancer Survivors: A Randomized Controlled Trial JMIR Cancer 1(2) e12

Fong, D. Y. T., Ho, J. W. C., Hui, B. P. H., Lee, A. M., Macfarlane, D. J., Leung, S. S. K., ... Cheng, K. -k. 2012. Physical activity for cancer survivors: meta-analysis of randomised controlled trials. Bmj, 344(jan30 5), e70-e70. https://doi.org/10.1136/bmj.e70

Hawkes A L, Patrao T A, Green A and Aitken J F 2012 CanPrevent: A telephone-delivered intervention to reduce multiple behavioural risk factors for colorectal cancer BMC Cancer 12(1) 1

Hatchett A, Hallam J S and Ford M A (n.d) Evaluation of a social cognitive theory-based email intervention designed to influence the physical activity of survivors of breast cancer (2012) Psycho-Oncology 22(4) 829-36

Kuijpers W, Groen W G, Oldenburg H S A, Wouters M W J M, Aaronson N K and van Harten W H 2016 eHealth for Breast Cancer Survivors: Use, Feasibility and Impact of an Interactive Portal JMIR Cancer 2(1) e3

Lee M K, Yun Y H, Park H-A, Lee E S, Jung K H and Noh D-Y 2014 A Web-based self-management exercise and diet intervention for breast cancer survivors: Pilot randomized controlled trial International Journal of Nursing Studies, 51(12) 1557-567

Lustria, M. L. A., Cortese, J., Noar, S. M., \& Glueckauf, R. L. (2009). Computer-tailored health interventions delivered over the web: Review and analysis of key components. Patient Education and Counseling, 74(2), 156-173. https://doi.org/10.1016/j.pec.2008.08.023

Mateo Flores , G., Granado-Font, E., Ferré-Grau, C., \& Montaña-Carreras, X. (2015). Mobile Phone Apps to Promote Weight Loss and Increase Physical Activity: A Systematic Review and Meta-Analysis. Journal of Medical Internet Research, 17(11), e2.Bayliss, E. A., Ellis, J. L., Shoup, J. A., Zeng, C., McQuillan, D. B., \& Steiner, J. F. (2015). Effect of continuity of care on hospital utilization for seniors with multiple medical conditions in an integrated health care system. Annals of Family Medicine, 13(2), 123-129. doi:10.1370/afm.1739

McCarroll M L, Armbruster S, Pohle-Krauza R J, Lyzen A M, Min S, Nash D W and von Gruenigen V E 2015 Feasibility of a lifestyle intervention for overweight/obese endometrial and breast cancer survivors using an interactive mobile application. Gynecologic Oncology, 137(3), 508-15

McCarroll M L, Armbruster S, Pohle-Krauza R J, Lyzen A M, Min S, Nash D W and von Gruenigen V E 2015 Feasibility of a lifestyle intervention for overweight/obese endometrial and breast cancer survivors using an interactive mobile application. Gynecologic Oncology, 137(3) 508-15 
Ofcom. 2017. The Communications Market: Digital Progress Report. Communications, https://www.ofcom.org.uk/research-and-data/tv-radi.

Park, J., Lee, J., Oh, M., Park, H., Chae, J., Kim, D., ... Jeon, J. Y. 2016. The effects of oncologist's exercise recommendation on the level of exercise and quality of life in breast and colorectal cancer survivours: Randomized Controlled Trial. Cancer, 121(16), 2740-2748. https://doi.org/10.1002/cncr.29400.The

Patrick, Pratt, \& Sallis. 2009. The healthcare sector's role in the U.S. national physical activity plan. Journal of Physical Activity \& Health, 6 Suppl 2, S211-9.

Puszkiewicz P, Roberts A L, Smith L, Wardle J and Fisher A 2016 Assessment of Cancer Survivors' Experiences of Using a Publicly Available Physical Activity Mobile Application JMIR Cancer 2(1)

Pope, Z., Lee, J. E., Zeng, N., Lee, H. Y., \& Gao, Z. (2018). Feasibility of smartphone application and social media intervention on breast cancer survivors' health outcomes. Translational Behavioral Medicine, iby002. https://doi.org/10.1093/tbm/iby002

Rabin C, Dunsiger S, Ness K K, and Marcus B H 2011 Internet-Based Physical Activity Intervention Targeting Young Adult Cancer Survivors Journal of Adolescent and Young Adult Oncology 1(4) 188-94

Roberts A L, Fisher A, Smith L, Heinrich M and Potts H W W 2017 Digital health behaviour change interventions targeting physical activity and diet in cancer survivors: a systematic review and meta-analysis Journal of Cancer Survivorship 11(6) 704-19

Stewart, B. W., \& Wild, C. P. (2014). World cancer report 2014. World Health Organization, 1-2. https://doi.org/9283204298WHO. (2014). World cancer report 2014. World Health Organization, 1-2. https://doi.org/9283204298

Schmid D and Leitzmann M F 2014 Association between physical activity and mortality among breast cancer and colorectal cancer survivors: a systematic review and meta-analysis Annals of Oncology 25(7) 1293-311

Short C, Rebar A, James E, Duncan M, Courneya K, Plotnikoff R and Vandelanotte C 2017 How do different delivery schedules of tailored web-based physical activity advice for breast cancer survivors influence intervention use and efficacy? Journal of Cancer Survivorship 11(1) 80-91

Valle C G, Tate D F, Mayer D K, Allicock M and Cai J 2014 A Randomized Trial of a Facebook-based Physical Activity Intervention for Young Adult Cancer Survivors 7(3) 355-68

Valle C G and Tate D F 2017 Engagement of young adult cancer survivors within a Facebook-based physical activity intervention Translational Behavioral Medicine 7(4) 667-79

Vallance, J. K. H., Courneya, K. S., Plotnikoff, R. C., Yasui, Y., \& Mackey, J. R. (2007). JOURNAL OF CLINICAL ONCOLOGY Randomized Controlled Trial of the Effects of Print Materials and Step Pedometers on Physical Activity and Quality of Life in Breast Cancer Survivors, 25(17). https://doi.org/10.1200/JC0.2006.07.9988

Valle C G, Tate D F, Mayer D K, Allicock M and Cai J 2015 Exploring Mediators of Physical Activity in Young Adult Cancer Survivors: Evidence from a Randomized Trial of a Facebook-Based Physical Activity Intervention Journal of Adolescent and Young Adult Oncology 4(1) 26-33 